\title{
Evidence for different behaviors of atmospheric glass alteration as a function of glass composition
}

\author{
Fanny Alloteau $\mathbb{D}^{1,2}$, Odile Majérus $\mathbb{D}^{2 凶}{ }^{凶}$, Valentina Valbi $\mathbb{D}^{1,2}$, Isabelle Biron ${ }^{1}$, Patrice Lehuédé ${ }^{1}$, Daniel Caurant ${ }^{2}$, \\ Thibault Charpentier (iD ${ }^{3}$ and Antoine Seyeux ${ }^{2}$
}

The glass composition is a determining parameter that influences the glass chemical durability, particularly in atmospheric conditions (defined by the relative humidity, $\mathrm{RH},<100 \%)$. This is obvious in the field of the cultural heritage $(\mathrm{CH})$, where some glass compositions qualified as unstable show advanced signs of degradation under atmosphere, while others seem, on the contrary, stable. This study investigates the differences between stable and unstable glass compositions regarding the phenomenology of the atmospheric glass alteration, by means of accelerated ageing of three glass replicas followed by the characterization of their alteration layers at different scales. Over the same ageing period and experimental conditions, the two glass compositions qualified as unstable develop thick hydrated layers and a thin top layer of carbonate precipitates. Their hydrated layers are depolymerized, and they remarkably retain alkalis and non-bridging oxygens in a dense network of hydrogen bonds, as demonstrated by ${ }^{29} \mathrm{Si}$ and ${ }^{1} \mathrm{H}$ MAS NMR. On the contrary, the stable glass composition shows a considerably thinner hydrated layer and, relatively, a higher amount of carbonates on the surface. In unstable glasses, the retention of a significant proportion of alkalis and NBOs, probably by maintaining a basic character to the hydrated layer, seems comparatively a destabilizing factor sustaining hydration by fast network hydrolysis.

npj Materials Degradation (2020)4:36; https://doi.org/10.1038/s41529-020-00138-1

\section{INTRODUCTION}

Oxide glasses have been produced since the Neolithic period, $\sim 4000 \mathrm{BC}$ for first glazes on decorated ceramics, $\sim 2500 \mathrm{BC}$ for the first beads totally made of glass. Most historical glass artefacts have been conserved in buried environment, showing diverse and complicated patterns of alteration, due to the interaction with groundwater and environmental materials. Other glass art objects, dating back from the Egyptian, Celtic or Roman Antiquity for a few, and many from the end of the middle-age period up to now, have never been buried and could be conserved in the atmosphere in the collector's homes and museums ${ }^{1}$. Depending on their composition and on the atmospheric conditions of their conservation, these glass objects show various degrees of alteration, from the unaltered state to the heavy deteriorated state where the object looses its mechanical integrity ${ }^{1,2}$. This alteration has been very early recognized ${ }^{3}$, and systematic studies have been engaged since the 1960 s (see a short review in ref. ${ }^{4}$ ). These research efforts based on the observation of ancient glasses and the artificial ageing of glass replicas have led to two essential results reaching a consensus in both the scientific and conservation communities ${ }^{5}$ : (i) the macroscopic signs of the atmospheric glass alteration are always the same and very specific. Five stages of alteration have been proposed by $\mathrm{Koob}^{2}$ that encompass two phenomena: the recurring formation of salts on the surface, and the fracturing of the surface. Both are due to the hydration of the glass surface in the humid atmosphere. The deliquescence of certain salts may cause a wet, oily aspect reflected in the terms "sweating" or "weeping glass" for these glass compositions. The fracturing of the hydrated glass layer is named "crizzling", it consists of a network of cracks intersecting at right angles ${ }^{6,7}$. These cracks are probably produced by the release of tensile stresses in the fragile layer, similarly as the cracking of fragile paint layers $^{8}$ and of certain ceramic glazes ${ }^{9}$. Crizzling can be accompanied by delamination or "flaking". Advanced crizzling causes loss of matter and eventually the disintegration of the object. (ii) The glass composition is the determining factor to glass alteration variability, with glasses being roughly divided into two groups (although there is a continuity of compositions between the two groups): the stable glass compositions, and the unstable ones. Heavy deteriorated glasses belong to the unstable glass compositions, while moderately deteriorated glasses may belong to unstable compositions conserved in good preventive conditions, or to stable compositions conserved in aggressive conditions (as, e.g., confined humidity). Although the distinction between stable and unstable compositions has been established for a long time, there is no precise idea of what compositional parameter classifies a glass as "stable" or "unstable". Most unstable glass compositions, mainly produced in post medieval Europe, have a low content in stabilizer oxides $(\mathrm{CaO}$ and $\mathrm{MgO})$ and a high content in alkali oxides $\left(\mathrm{Na}_{2} \mathrm{O} \text { and/or } \mathrm{K}_{2} \mathrm{O}\right)^{10,11}$ as outlined by the triangular diagram of Iliffe and Newton ${ }^{12}$. However, exceptions to this rule and other influent compositional parameters indicate that it is more probably the "overall composition that seems to be the main factor that controls instability"4.

In this paper, we try to bring new elements about the question of "why are some glass compositions stable and other unstable to atmospheric alteration?". Three glass compositions, representative of compositions of the cultural heritage $(\mathrm{CH})$ and simplified to their six major oxides, have been chosen for a comparative experimental study. Two compositions are known as unstable, bearing a low content in $\mathrm{CaO}+\mathrm{MgO}(\leq 5 \mathrm{wt} \%)$ and high content in alkali oxides $\left(\sim 22 \mathrm{wt} \% \mathrm{~K}_{2} \mathrm{O} \text { or } \mathrm{K}_{2} \mathrm{O}+\mathrm{Na}_{2} \mathrm{O}\right)^{10,12,13}$. The other composition is a stable soda-lime composition with a higher content in $\mathrm{CaO}+\mathrm{MgO}$ (10.5 wt\%), a similar content in alkali oxides

${ }^{1}$ Centre de Recherche et de Restauration des Musées de France (C2RMF), F-75001 Paris, France. ${ }^{2} \mathrm{PSL}$ University, Chimie Paristech, CNRS, Institut de Recherche de Chimie Paris, F75005 Paris, France. ${ }^{3}$ NIMBE, CEA, CNRS, Université Paris-Saclay, CEA Saclay, F-91191 Gif-sur-Yvette, France. ${ }^{\otimes}$ email: Odile.Majerus@chimieparistech.psl.eu 
Table 1. Glass compositions and powder properties.

\begin{tabular}{|c|c|c|c|c|c|c|c|c|c|c|}
\hline Glass name and period & & $\mathrm{SiO}_{2}$ & $\mathrm{Al}_{2} \mathrm{O}_{3}$ & $\mathrm{MgO}$ & $\mathrm{CaO}$ & $\mathrm{Na}_{2} \mathrm{O}$ & $\mathrm{K}_{2} \mathrm{O}$ & $\mathrm{NBO} / \mathrm{Si}$ & $\begin{array}{l}(\mathrm{CaO}+\mathrm{MgO}) / \\
\mathrm{SiO}_{2}\end{array}$ & $\begin{array}{l}\text { Particle size and specific surface }\left(\mathrm{cm}^{2} \mathrm{~g}^{-1}\right) \text { of } \\
\text { glass powder }\end{array}$ \\
\hline \multirow{2}{*}{$\begin{array}{l}\text { A-Mixed-alkali silicate } \\
\text { Middle Age, Renaissance, } \\
\text { XIX }\end{array}$} & wt.\% & 71.3 & 0.8 & 0.8 & 5.0 & 11.0 & 11.0 & \multirow[t]{2}{*}{0.66} & \multirow[t]{2}{*}{0.09} & \multirow{2}{*}{$\begin{array}{l}5-10 \mu \mathrm{m} \\
7800 \pm 900\end{array}$} \\
\hline & mol.\% & 74.2 & 0.5 & 1.2 & 5.6 & 11.1 & 7.3 & & & \\
\hline \multirow{2}{*}{$\begin{array}{l}\text { P-Potassium silicate } \\
X V I^{\text {th }}-X V I I I^{\text {th }}\end{array}$} & wt.\% & 75.8 & 0.3 & 0.2 & 2.0 & 1.5 & 20.2 & \multirow{2}{*}{0.44} & \multirow[t]{2}{*}{0.03} & \multirow{2}{*}{$\begin{array}{l}5-10 \mu \mathrm{m} \\
7800 \pm 900\end{array}$} \\
\hline & mol.\% & 81.7 & 0.2 & 0.3 & 2.3 & 1.6 & 13.9 & & & \\
\hline \multirow{2}{*}{$\begin{array}{l}\text { SL-Soda-lime silicate } \\
\text { Since Antiquity }\end{array}$} & wt.\% & 66.8 & 2.5 & 3.0 & 7.5 & 18.0 & 2.1 & \multirow[t]{2}{*}{0.90} & \multirow[t]{2}{*}{0.19} & \multirow{2}{*}{$\begin{array}{l}2-5 \mu \mathrm{m} \\
17500 \pm 1000\end{array}$} \\
\hline & mol.\% & 67.0 & 1.5 & 4.6 & 8.1 & 17.5 & 1.4 & & & \\
\hline
\end{tabular}

Composition of the three glass replicas of this study, as measured by particle-induced X-ray emission (PIXE). The NBO molar content is given by 2 (MgO $+\mathrm{CaO}$ $\left.+\mathrm{Na}_{2} \mathrm{O}+\mathrm{K}_{2} \mathrm{O}\right)-\mathrm{Al}_{2} \mathrm{O}_{3}$, where "MgO" denotes the molar content in MgO oxide.

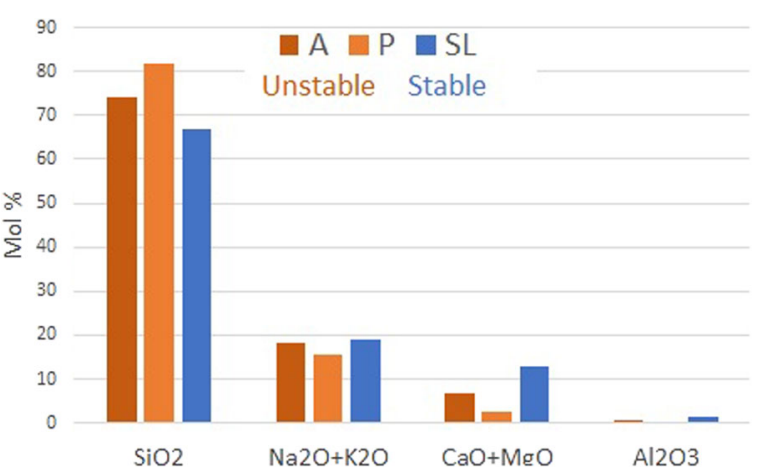

Fig. 1 Glass compositions. Comparison of the molar compositions of the three glasses investigated in this study.

$\left(\sim 20\right.$ wt $\% \mathrm{Na}_{2} \mathrm{O}$ ) and a higher content in $\mathrm{Al}_{2} \mathrm{O}_{3}$ (2.5 wt $\%$ compared with $<1 \mathrm{wt} \%)$. Polished glass plates and calibrated glass powders have been aged for various times at $80^{\circ} \mathrm{C}$ or $40^{\circ} \mathrm{C}$ at a relative humidity, $\mathrm{RH}$, of $85 \%$, and the aged glasses have been characterized using a combination of analytical methods from the macroscopic to the atomic scale. In particular, the compositional and structural information about the alteration layer is crucial to better understand the alteration mechanisms, as it has been shown in a previous detailed study of the unstable mixedalkali lime silicate glass ${ }^{14,15}$. In this study, the comparison of the alteration layers of the three glass compositions jointly with their hydration kinetics allows to discuss possible factors underlying the compositional effect on glass alteration in atmospheric conditions.

\section{RESULTS}

Preliminary remarks

The compositions of the three glass replicas are given in Table 1, together with the periods of fabrication that these compositions are representative of in the $\mathrm{CH}$. The compositions referred to as " $\mathrm{A}$ " and " $\mathrm{P}$ " are a mixed-alkali ( $\mathrm{Na}$ and $\mathrm{K}$ ) lime silicate glass and a potassium lime silicate glass, respectively, both recognized as unstable compositions of the $\mathrm{CH}$. The composition referred to as "SL" is a soda-lime silicate glass composition considered as "stable" in the $\mathrm{CH}$. For a better comparison, the three compositions are also depicted in the bar diagram of Fig. 1. Note that their total amount of alkali oxides is similar. They essentially differ in the nature of the alkalis $(\mathrm{Na}$ and $\mathrm{K})$ and in the $(\mathrm{CaO}+\mathrm{MgO}) / \mathrm{SiO}_{2}$ ratio (Table 1). The SL glass also contains a triple molar amount of $\mathrm{Al}_{2} \mathrm{O}_{3}$. After their synthesis by a melt-quenching method, these glasses have been prepared as polished plates $\left(10 \times 10 \times 3 \mathrm{~mm}^{3}\right)$ and as calibrated powders, of which particle sizes are given in Table 1. These particle sizes have been selected in order to obtain alteration in the bulk of glass grains and enable the characterization of the alteration layer by spectroscopic techniques (Raman and NMR). Polished plates and powders have been aged in unsaturated relative humidity $(85 \%)$ at $40^{\circ} \mathrm{C}$ or at $80^{\circ} \mathrm{C}$ for various periods of time, using either a climatic chamber or a hermetic box with a saturated saline solution of $\mathrm{KCl}$. When using the climatic chamber, a $\mathrm{T}$ (temperature) and \%RH ramp was programmed at the beginning and at the end of the ageing test, ensuring that the dew point was never reached during the ramps. At the end of the ageing test, the samples were cooled down to $20^{\circ} \mathrm{C}$ and dried at $35 \mathrm{RH} \%$. Then, the aged glass plates were stored in the ambient atmosphere of the laboratory, of which $\mathrm{T}$ and $\mathrm{RH} \%$ fluctuated in the ranges [17-29 ${ }^{\circ} \mathrm{C}$ ] and [25-60\%] (with a few summer days superior to $60 \%$ ) over a 1-year period, and the aged glass powders were stored in closed Eppendorf tubes in the laboratory. When using a hermetic box, because no cooling and drying ramp could be carried out with this device, the samples were removed and dried in desiccators with silica gel for a few days, before they were stored in the ambient atmosphere of the laboratory (glass plates) or in closed Eppendorf tubes (glass powders). The aged powders were characterized as shortly as possible of the time of their drying. We emphasize that during their ageing and their storage before the characterizations, the glass samples have never undergone any contact with water in a condensed state (as liquid nor as $100 \% \mathrm{RH}$ ). Furthermore, all characterizations have been performed without any washing or wiping of the samples. SEM-EDX observations were carried out at the glass surface or at the edge of a fresh fracture of the glass plates. The characterization of the alteration salts on the glass surface was supplemented by XRD and Raman measurements (carbonate precipitates are considered as salts). Tof-SIMS profile measurements were carried out as much as possible on clean surface areas between the alteration salts, and the presence of these salts has been considered in the interpretation of the data. These precautions are important to be able to study the products of the atmospheric glass alteration, while avoiding their dissolution or transformation due to liquid water ${ }^{14}$. At last, Raman and MAS NMR spectra have been measured on the aged glass powders.

Generally, the alteration layers of the three glasses are composed of at least two sub-layers: a hydrated layer at the interface with the pristine glass, and a top layer of Ca- and alkalicarbonate salts that may be spread out over the glass surface (if they are not numerous), or that may form a continuous crust. However, beyond this overall picture, considerable differences are noticed between the three compositions. As expected, the SL glass develops an alteration layer with a far lower thickness compared with the two other glasses, which justifies its classification as "stable" (i.e., more chemically durable) as opposed to the other two "unstable" glass compositions. In the following, these alteration layers are described in terms of microstructure, 

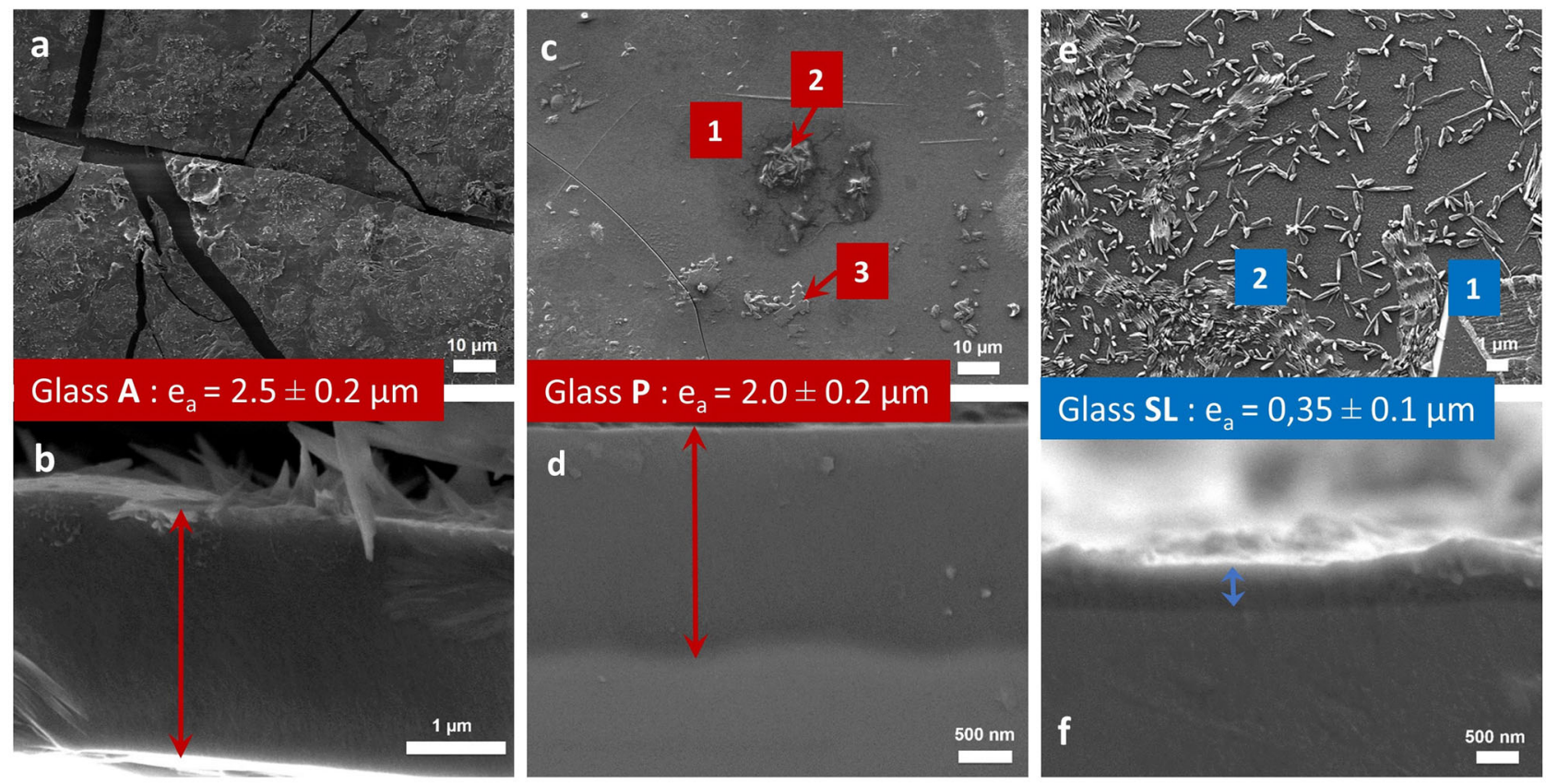

Fig. 2 Alteration layers of the three glasses after a 6-month ageing at $\mathbf{4 0}{ }^{\circ} \mathbf{C}$ and $85 \mathbf{R H} \%$. Secondary electrons SEM images of glass plates after an ageing test at $40^{\circ} \mathrm{C}, 85 \mathrm{RH} \%$, for 6 months (hermetic box containing a saline solution of $\mathrm{KCl}$ in $\mathrm{H}_{2} \mathrm{O}$ ), $\mathbf{a}$, $\mathbf{c}$, e: surfaces, and $\mathbf{b}$, $\mathbf{d}$, f: edges. In $\mathbf{b}$, $\mathbf{d}$ and $\mathbf{f}$ the double arrow corresponds to the thickness of the alteration layer. $\mathbf{a}$ and $\mathbf{b}$ : glass A; $\mathbf{c}$ and $\mathbf{d}$ : glass $\mathrm{P} ; \mathbf{e}$ and $\mathbf{f}:$ glass SL. The scale bars are $10 \mu \mathrm{m}$ (a and $\mathbf{c}), 1 \mu \mathrm{m}$ (e and $\mathbf{b})$ and $500 \mathrm{~nm}$ (d and f).

\begin{tabular}{|c|c|c|c|c|}
\hline & $80^{\circ} \mathrm{C} \mathrm{V72h}$ & $40^{\circ} \mathrm{C} \mathrm{V3m}$ & $40^{\circ} \mathrm{C} \mathrm{V6m}$ & $40^{\circ} \mathrm{C} \mathrm{V9m}$ \\
\hline A & $13 \pm 1 \mu \mathrm{m}$ & $1 \pm 0.2 \mu \mathrm{m}$ & $2.5 \pm 0.2 \mu \mathrm{m}$ & $6.5 \pm 0.5 \mu \mathrm{m}$ \\
\hline SL & $<100 \mathrm{~nm}^{*}$ & $0.15 \pm 0.02 \mu \mathrm{m}^{*}$ & $0.35 \pm 0.1 \mu \mathrm{m}$ & $0.45 \pm 0.1 \mu \mathrm{m}^{*}$ \\
\hline$P$ & $10 \pm 0.1 \mu \mathrm{m}$ & $1 \pm 0.2 \mu \mathrm{m}$ & $2 \pm 0.2 \mu \mathrm{m}$ & \\
\hline \multicolumn{5}{|c|}{$\begin{array}{l}\text { Alteration layer thicknesses }\left(e_{a}\right) \text { of the three glass replica compositions ( } \mathrm{A} \text {, } \\
\mathrm{SL} \text { and } \mathrm{P} \text { ) for the same ageing programme }\left(80^{\circ} \mathrm{C}, 85 \% \mathrm{RH} \text { (climatic oven) or }\right. \\
\left.40^{\circ} \mathrm{C}, 85 \% \mathrm{RH} \text { (hermetic box containing a saline solution of } \mathrm{KCl} \text { in } \mathrm{H}_{2} \mathrm{O}\right) \text { ), as } \\
\text { determined by SEM observations on the edge, or }\left({ }^{*}\right) \text { from ToF-SIMS } \\
\text { profiles. The notation } \mathrm{Vxh} / \mathrm{m} \text { refers to the duration of the ageing test in } \\
\text { hours (h) or in months }(\mathrm{m}) \text {. }\end{array}$} \\
\hline
\end{tabular}

thickness and chemical composition including the water content and atomic structure.

Microstructure and thickness of the alteration layers

The morphologies and microstructures of the alteration layers of the three glass compositions after 6 months of ageing at $85 \mathrm{RH} \%$ and $40^{\circ} \mathrm{C}$ are shown in Fig. 2. The thickness of the alteration layers (noted $e_{a}$ ), as measured either by ToF-SIMS or by SEM on the edge of the glass plates, is reported in Table 2 and Fig. 3 . This thickness includes the top salt layer, except the biggest salt particles distributed on the surface (as in Fig. 2b).

The $e_{a}$ value is smaller for the SL glass by a factor of about 10 at $40{ }^{\circ} \mathrm{C}$, and even 100 at $80^{\circ} \mathrm{C}$, with respect to the two other glass compositions. It never exceeds $450 \mathrm{~nm}$, while the other glasses are hydrated up to a depth of $6.5 \mu \mathrm{m}$ at $40^{\circ} \mathrm{C}$ (glass $\mathrm{A}, 9$ months) and $13 \mu \mathrm{m}$ at $80^{\circ} \mathrm{C}$ (glass $\mathrm{A}, 72 \mathrm{~h}$ ). The glass $\mathrm{P}$ composition seems a little bit more durable than the glass $A$ composition, because a slightly lower alteration layer thickness is observed after an extended ageing $\left(6\right.$ months at $40^{\circ} \mathrm{C}$ and $72 \mathrm{~h}$ at $\left.80^{\circ} \mathrm{C}\right)$.

The alteration layers of the $\mathrm{A}$ and $\mathrm{P}$ glasses are composed of a thick hydrated layer (about $2 \mu \mathrm{m}$ after 6 months at $40^{\circ} \mathrm{C}$, Fig. 2 ), and a thin top layer of salts. For glass $A$, the biggest salts are

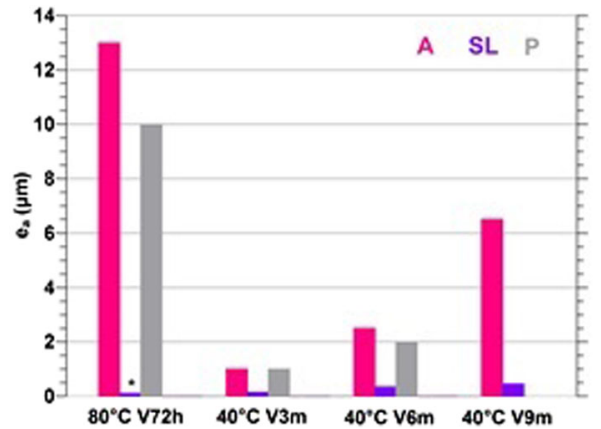

Fig. 3 Alteration layer thickness. Comparison of the alteration layer thicknesses $\left(e_{a}\right)$ of the three glass replica $(A, S L$ and $P)$ for the same ageing programme at $80^{\circ} \mathrm{C}, 85 \% \mathrm{RH}$ (climatic oven) or at $40^{\circ} \mathrm{C}$, $85 \% \mathrm{RH}$ (hermetic box containing a saline solution of $\mathrm{KCl}$ in $\mathrm{H}_{2} \mathrm{O}$ ) (numerical values are reported in Table 2). The notation $\mathrm{Vxh} / \mathrm{m}$ refers to the duration of the ageing test in hours $(h)$ or in months $(m) .\left(^{*}\right) e_{a}$ could not be determined by SEM observations and is estimated below $100 \mathrm{~nm}$. Due to the few number of polished samples for glass $\mathrm{P}$, the V9m measurement for this glass is lacking.

calcite and the small needle-shaped salts are Na carbonates and/ or mixed $\mathrm{Na}, \mathrm{Ca}$ carbonates. The hydrated layer cracks during the cooling and drying of the glass after 3 months of ageing $\left(e_{a}\right.$ $\sim 1 \mu \mathrm{m})$ and it cracks and flakes after 6 months of ageing $\left(e_{a}\right.$ $\sim 2.5 \mu \mathrm{m}$ ). The flaking occurs at the interface with the pristine glass, as demonstrated by the EDX analysis of the glass below the flakes. The microstructure of the alteration layer of this glass has been more extensively described as a function of temperature and time elsewhere ${ }^{14,15}$. For glass $P$, the salts are less numerous than in glass A. Optical microscopy examination indicates the occurrence of deliquescence (not shown) that vanishes in the high-vacuum chamber of the SEM. The salts form a very thin layer that is distinguished through the dark areas on the SEM images due to the topological and chemical contrast captured with secondary electrons (Fig. 2c label 1 and Fig. 4, top area of the left image). This 

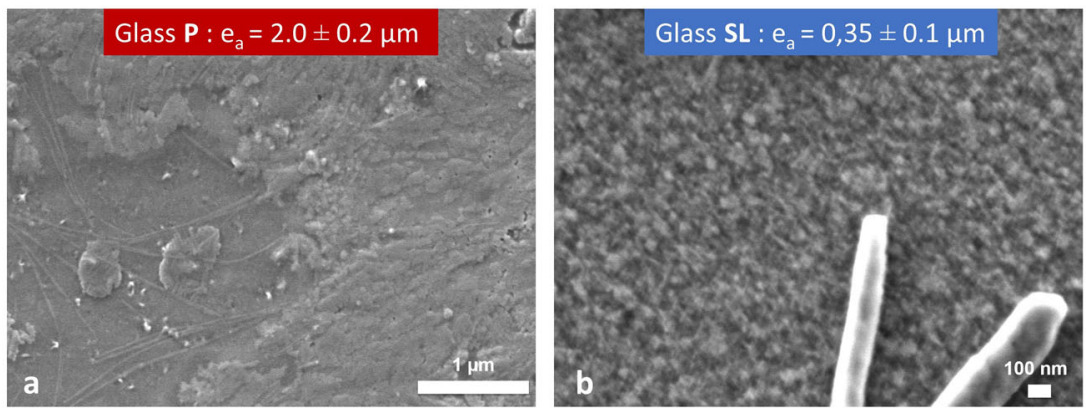

Fig. 4 Alteratio- layer surface below the carbonate salts. High-magnification secondary electrons SEM images of the surface of the P (a) and $\mathrm{SL}$ (b) glass plates aged at $40^{\circ} \mathrm{C}, 85 \mathrm{RH} \%$ for 6 months, secondary electron mode. The scale bars are $1 \mu \mathrm{m}(\mathbf{a})$ and $100 \mathrm{~nm}$ (b).

\begin{tabular}{|c|c|c|c|c|c|c|c|c|c|c|c|c|}
\hline & $\mathrm{O}$ & $\mathrm{Na}$ & $\mathrm{Mg}$ & $\mathrm{Al}$ & $\mathrm{Si}$ & K & $\mathrm{Ca}$ & Calculated O & $\mathrm{Na} / \mathrm{Si}$ & $\mathrm{K} / \mathrm{Si}$ & $\mathrm{Ca} / \mathrm{Si}$ & $\mathrm{H}_{2} \mathrm{O}^{*} w t \%$ \\
\hline A pristine & 59.5 & 7.58 & 0.42 & 0.33 & 25.2 & 4.98 & 1.90 & 59.5 & 0.30 & 0.20 & 0.075 & - \\
\hline P pristine & 61.2 & 1.05 & 0.11 & 0.13 & 27.4 & 9.33 & 0.78 & 61.2 & 0.04 & 0.34 & 0.03 & - \\
\hline P V6m $15 \mathrm{kV}$ & 65.0 & 0.78 & 0.09 & 0.12 & 26.6 & 7.13 & 0.28 & 57.7 & 0.03 & 0.27 & 0.01 & 6.2 \\
\hline
\end{tabular}

thin crust is enriched in $\mathrm{K}$ and $\mathrm{C}$ as shown by EDX. Bigger crystalline clusters (Fig. 2c, label 2) enriched in $\mathrm{K}, \mathrm{Na}, \mathrm{S}$ and $\mathrm{O}$ are spread out over the surface, and large flat crystals enriched in $\mathrm{Ca}$, $\mathrm{C}$ and assigned to calcite after their identification by Raman spectroscopy, are also present (Fig. 2c, label 3). The hydrated layer of glass $P$ is cracked after 6 months of ageing (cracks are visible in Fig. 2c) but it is not flaked, or delaminated, contrary to glass $A$. The weaker tendency of glass $\mathrm{P}$ to crack and flake is also observed at $80^{\circ} \mathrm{C}$ (not shown). The hydrated layer of glass $\mathrm{P}$ contains a high amount of $\mathrm{K}^{+}$ions, as it will be demonstrated later (Table 3), while the hydrated layer of glass A contains $\mathrm{Na}^{+}$ions and a lower amount of $\mathrm{K}^{+}$ions. It is possible that the high content in $\mathrm{K}^{+}$ions prevents the hydrated layer from a too large shrinkage during the drying, reducing the internal tensile stress and thus its tendency for cracking. A reason for that may be that $\mathrm{K}^{+}$ions are big and probably less surrounded by molecular water than $\mathrm{Na}^{+}$ions ${ }^{15}$. On the other hand, the alteration layer of SL glass is characterized by both a large amount of salts on the top and a thin hydrated layer, the ratio between the surface amount of salts and the hydratedlayer thickness being considerably greater than for the other two glasses. This is consistent with the fact that the hydrated layer is more depleted in alkalis (see later, Table 3). Calcite salts are the first salts to be observed, and they are the biggest salts, well recognizable with their flat and faceted shape (label 1 in Fig. 2e). Together with calcite, numerous needle-shaped $\mathrm{Na}$ - and $\mathrm{Na}, \mathrm{Ca}$ carbonates with sub-micrometric size are observed similarly to glass A (label 2). Below this top layer of carbonates, the thin hydrated layer is not homogeneous as for glasses $A$ and $P$, but instead is divided into two sub-layers. The high-magnification SEM image in Fig. 4 shows the surface aspect of the layer, which is obviously rough and porous at the $10-\mathrm{nm}$ scale, contrary to the other glasses. Below this porous surface layer evoking silica precipitation, a homogeneous (at the SEM scale) hydrated layer is suspected but difficult to observe by SEM on the edge because of its thinness. STEM observation has been carried out on these aged $\mathrm{SL}$ glass plates (Fig. 5). Because they were unstable under the electron beam, STEM-EDX analysis, as well as our further attempt to make and observe a FIB thin sample, did not succeed. The STEM images show two early stages of the alteration of SL glass (22 days at $40^{\circ} \mathrm{C}$ and 6 days at $80^{\circ} \mathrm{C}, 85 \mathrm{RH} \%$ ). Although the division of the hydrated layer into two sub-layers is not distinguishable at $40^{\circ} \mathrm{C}$, 22 days $\left(e_{a} \sim 50 \mathrm{~nm}\right)$, it is well put in evidence at $80^{\circ} \mathrm{C}, 6$ days $\left(e_{a}\right.$ $\sim 100 \mathrm{~nm}$ ) (labels 2 and 3 in Fig. 5b). This hydrated layer subdivision will be confirmed by the ToF-SIMS depth profiles in the next section.

Chemical composition of the alteration layers

The chemical analysis of the hydrated layers has been carried out by SEM EDX at the surface of the glass plates aged at $40^{\circ} \mathrm{C}, 85 \mathrm{RH}$ $\%$ for 6 months and the results are given in Table 3. As far as possible, the analyses were performed outside the calcite and alkali carbonate salts. The pristine glasses were used as standards for the quantification. The contributions of the Pt layer and the pristine glass underneath the hydrated layer, were taken into account in the STRATAGem software by using a model of stacked layers with known thickness. The analyses totalized 91-97 wt\%, the difference to $100 \mathrm{wt} \%$ being attributed to the contribution of protons (for about $1 \mathrm{wt} \%$, according to the $\mathrm{H}_{2} \mathrm{O}$ content of about $10 \mathrm{wt} \%$, Table 3 ) and to the porosity of the hydrated layer. In Table 3 , the results are given in at $\%$ normalized to $100 \%$. The difference between the at $\% \mathrm{O}$ measured by EDX and the at $\% \mathrm{O}$ calculated by stoichiometry is attributed to water that is tightly bound in the hydrated layer (as $\mathrm{H}_{2} \mathrm{O}$ and $\mathrm{OH}$ ). The water content deduced from this analysis is given in the last column. All these analyses indicate that the alkalis depletion of the hydrated layer is limited, while the depletion in $\mathrm{Ca}^{2+}$ is more pronounced. The hydrated layers of the 

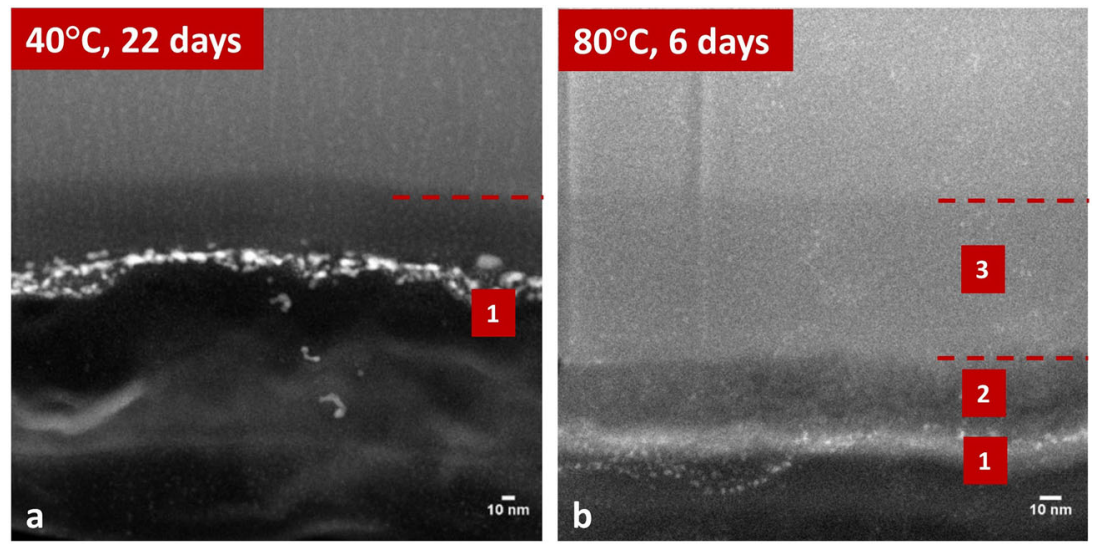

Fig. 5 STEM images of the edge of alteration layer of SL glass. STEM image (black field) of the edge of the $\mathrm{SL}$ glass plate aged at $40{ }^{\circ} \mathrm{C}$, $85 \mathrm{RH}$ $\%$ for 22 days (a), or at $80^{\circ} \mathrm{C}, 85 \mathrm{RH} \%$ for 6 days (b). The pristine glass corresponds to the light -grey zone on the top of both images. The bright layer labelled 1 on image a corresponds to platinum deposited in order to prepare FIB samples. On the contrary, there was no Pt deposited on the sample of image $\mathbf{b}$, the bright layer labelled 1 is assigned to alteration salts. The labels 2 and 3 correspond to the alteration layer decomposed into two states. The scale bar is $10 \mathrm{~nm}$.

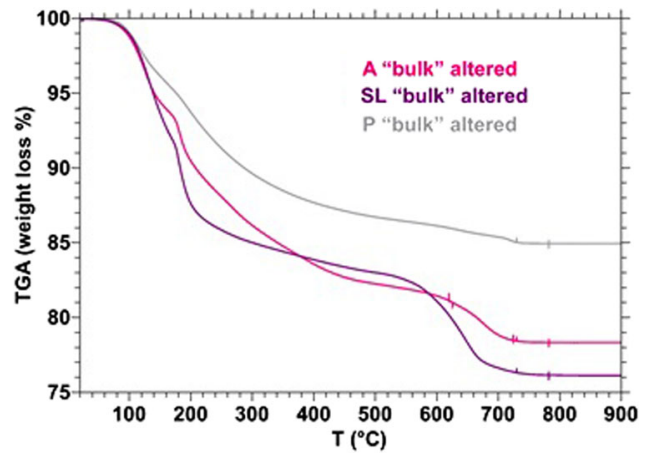

Fig. 6 Thermogravimetry of aged glass powders. Thermogravimetric analysis (TGA) of bulk altered glass powders after a 6-month ageing test at $40^{\circ} \mathrm{C}, 85 \% \mathrm{RH}$ (hermetic box containing a saline solution of $\mathrm{KCl}$ in $\mathrm{H}_{2} \mathrm{O}$ ) (particle sizes, A: $5-10 \mu \mathrm{m}, \mathrm{SL}: 2-5 \mu \mathrm{m}, \mathrm{P}$ : $5-10 \mu \mathrm{m})$.

glasses $\mathrm{A}$ and $\mathrm{P}$ still retain the majority of $\mathrm{Na}^{+}$and $\mathrm{K}^{+}$ions, with a relatively higher retention of $\mathrm{K}^{+}$ions. On the contrary, the hydrated layer of the glass SL has lost most of the $\mathrm{Na}^{+}$ions and half the $\mathrm{K}^{+}$ions.

The water content of the hydrated layer is between 6 and $9 \mathrm{wt}$ $\%$. Interestingly, it is slightly lower in glass P (6 wt\%), which might be due to a lower number of water molecules around the big alkali $\mathrm{K}^{+}$. The water content estimated by EDX can be compared with the mass loss measured by thermogravimetric analysis (TGA) of the bulk altered glass powders, aged for 6 months at $40^{\circ} \mathrm{C}, 85$ $\mathrm{RH} \%$ together with the glass plates, depicted in Fig. 6 . Because the water content by EDX refers to the tightly bound water not evaporated under the vacuum of the SEM chamber, it has to be compared with the mass loss measured beyond $150^{\circ} \mathrm{C}$ until about $550^{\circ} \mathrm{C}$. On this range, the mass loss is about $8 \mathrm{wt} \%$ for the three glass compositions, corroborating the EDX result. The mass loss between about 150 and $225^{\circ} \mathrm{C}$ corresponding to less tightly bound water is larger for glass SL. On the $225-550^{\circ} \mathrm{C}$ range, the gradual loss of the mass does not follow the same slope for the glasses $\mathrm{A}$ and $\mathrm{P}$ on the one hand, where it is progressive with significant contribution between 200 and $400{ }^{\circ} \mathrm{C}$, and for glass SL on the other hand, where it is moderate, most of the loss (about $70 \%$ ) occurring between 150 and $225^{\circ} \mathrm{C}$. These differences rely on different distributions of $\mathrm{H}$-bonding strengths in the two glass groups as put in evidence by ${ }^{1} \mathrm{H}$ MAS NMR of the powders (see below). From $600{ }^{\circ} \mathrm{C}$ up to about $740{ }^{\circ} \mathrm{C}$ is the mass loss due to the decomposition of carbonates, visible for the three compositions, although it is greater for glass SL as expected, considering the higher amount of carbonate salts on the top alteration layer of this glass.

The ToF-SIMS depth profiles of the three glass plates aged at $40^{\circ} \mathrm{C}, 85 \mathrm{RH} \%$ for 3 months are shown in Fig. 7. Although the profiles were measured outside the biggest carbonate salts (calcite), it was not possible to exclude the alkali salts that thus contribute to the profiles. As long as the ionic beam sputters these salts, the counts in alkali-bearing ionic species are increased, while the counts in species of the other glass elements are correspondingly decreased. Considering that these salts are thinner than the hydrated layer of glasses A and P (around $800 \mathrm{~nm}$ as indicated by the burgundy rectangle that marks the region of the interface between the alteration layer and the pristine glass), this effect is minimized near the interface with the pristine glass. These ToFSIMS profiles confirm the trends on the chemical composition of the hydrated layer measured by EDX: the alkalis are significantly retained, with $\mathrm{K}^{+}$ions more retained than $\mathrm{Na}^{+}$. The $\mathrm{Ca}^{2+}$ (and $\mathrm{Mg}^{2}$ ${ }^{+}$) ions are not retained in the hydrated layers of glasses $A$ and $S \mathrm{~L}$, while they are retained in the hydrated layer of glass $P$, except near the surface consistently with the presence of calcite. As regards the glass SL, of which hydrated layer is about $150-\mathrm{nm}$ thick, the first 10 nanometres contain Si but not at all Al. This very clear lack of Al element indicates that the surface layer outside the salts is made of some silica component that is distinct of the hydrated glass (which would contain Al as in A and P glasses). This finding can be linked to our SEM and STEM observations of a rough and porous sub-layer beneath the salts (Fig. 4 and zone 2 in Fig. 5) in glass SL. We propose that it is essentially composed of silica. This surface sub-layer reveals that the outside part of the hydrated glass has been entirely transformed into carbonate salts and silica, with the Al element being only located in the hydrated layer. Therefore, contrary to the other two glasses, the hydrated layer of glass SL is subdivided into two parts with the total transformation of the outer part.

\section{Structure of the alteration layers}

The atomic structure of the hydrated layers has been investigated using ${ }^{1} \mathrm{H}$ and ${ }^{29} \mathrm{Si}$ MAS NMR of the bulk altered glass powders, which have been aged at $40^{\circ} \mathrm{C}, 85 \mathrm{RH} \%$ together with the glass plates. The ${ }^{1} \mathrm{H}$ MAS NMR spectra, with direct acquisition (MAS) or with the Hahn echo acquisition sequence with varying echo time $\left(T_{E}\right)$, are depicted in Fig. 8. When the echo time is increased, the ${ }^{1} \mathrm{H}$ species undergoing strong homonuclear dipolar couplings are 

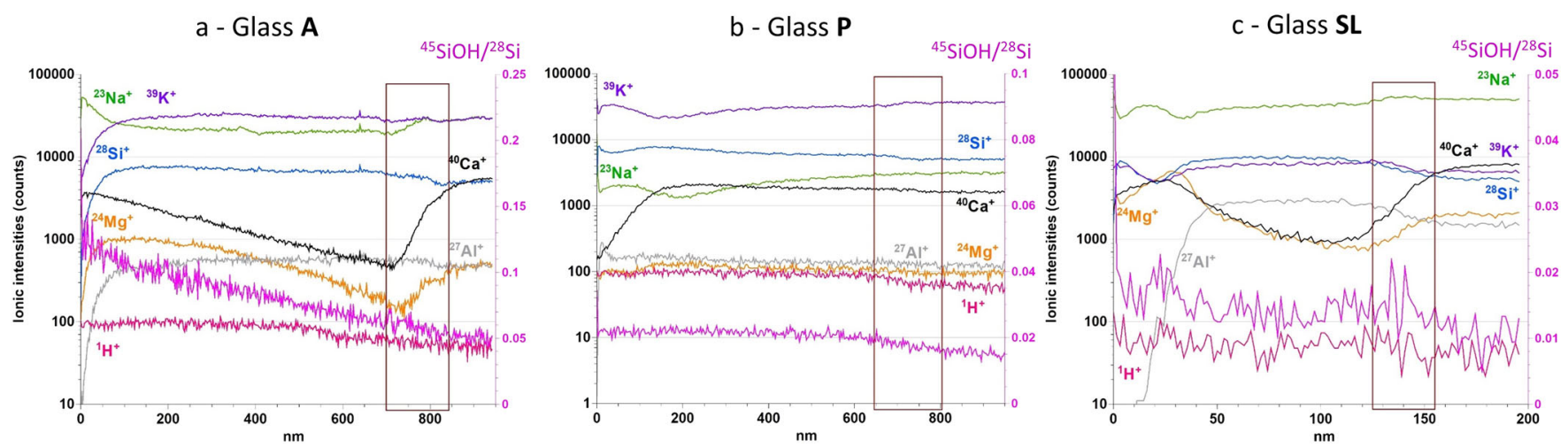

Fig. 7 TOF-SIMS depth profiles of glass plates aged for 3 months at $\mathbf{4 0}{ }^{\circ} \mathbf{C}, 85$ RH\%. Tof-SIMS depth composition profiles of glass plates after a 3-month ageing test at $40^{\circ} \mathrm{C}, 85 \% \mathrm{RH}$ (hermetic box containing a saline solution of $\mathrm{KCl}$ in $\mathrm{H}_{2} \mathrm{O}$ ). The region of the interface is marked with the burgundy rectangle. a Glass A; b glass P; c glass SL.
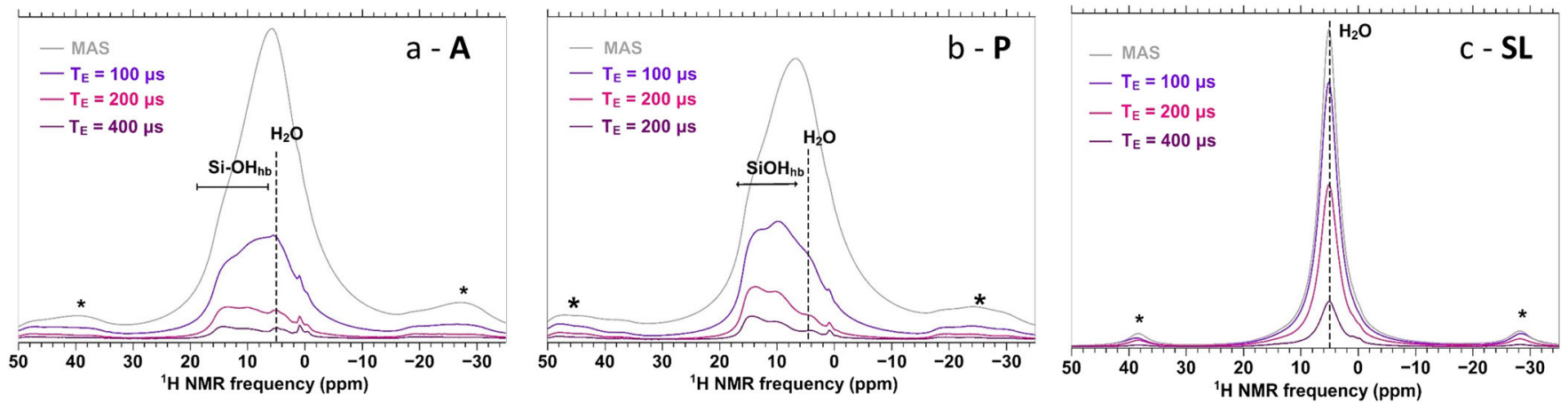

Fig. $8{ }^{1} \mathrm{H}$ MAS NMR spectra of aged glass powders. ${ }^{1} \mathrm{H}$ MAS NMR spectra of bulk altered glass powders after a 6 -month ageing test at $40{ }^{\circ} \mathrm{C}$, $85 \% \mathrm{RH}$ (hermetic box containing a saline solution of $\mathrm{KCl}$ in $\mathrm{H}_{2} \mathrm{O}$ ), direct ("MAS") or Hahn echo acquisition (with different echo delays " $\mathrm{T}_{\mathrm{E}}$ ") (hb: $\mathrm{H}$ bonded to the network, *:spinning sideband). a Glass $\mathrm{A} ; \mathbf{b}$ glass $\mathrm{P} ; \mathbf{c}$ glass SL.

filtered, because they have a short $\mathrm{T}_{2}$ relaxation time (they are thus not recovered in the echo). The spectra of the glass Ahydrated layer have been described and discussed elsewhere ${ }^{15}$. The intense contribution at +5 ppm, which disappears at high echo time, is assigned to molecular water (strong dipolar coupling). Besides, the wide distribution of intensity between about +3 and $+16 \mathrm{ppm}$ is assigned to the protons of silanol species, which undergo a wide distribution of $\mathrm{H}$-bonding strengths from weak (at $3 \mathrm{ppm}$ ) to very strong (at $16 \mathrm{ppm}$ ). The still intense spinning-side bands (even at high $\mathrm{T}_{\mathrm{E}}$ ) put in evidence the high density of the network of $\mathrm{H}$ bonds that is responsible for the strong dipolar couplings. The spectra are very similar for the hydrated layer of glass $P$ (Fig. 8b). The intensities are slightly higher towards the high-frequency side $(+16 \mathrm{ppm})$ with respect to glass A. In contrast, the spectra are dissimilar for the hydrated layer of glass SL. The major contribution by far is that of molecular water, while the contribution of silanol protons is almost absent.

The very strong $\mathrm{H}$ bonding (chemical shift near $16 \mathrm{ppm}$ ) visible in the A- and P-altered powders, corresponds to silanol protons bound to neighbouring non-bridging oxygens (NBOs) $)^{15-18}$. These silanol species are typically absent in the hydrated layers of silicate glasses altered in liquid water, often referred to as "gels", which do not bear any alkalis ${ }^{19}$. In the hydrated layers of this study produced in atmospheric conditions, all the silanol protons are embedded in a dense network of $\mathrm{H}$ bonds, which probably contributes to the stability of the network as in crystalline alkali silicate hydrates ${ }^{20}$. The presence of silanols strongly $\mathrm{H}$-bound to NBOs is consistent with the EDX and ToF-SIMS chemical analysis that reveals a high content in alkalis in the hydrated layers of these glasses. These strong $\mathrm{H}$-bonding contributions demonstrate that alkalis are still retained next to NBOs, although an unknown proportion of them may also be solvated within the hydrated layer. By contrast, the near absence of high chemical shift components in the altered powder of glass SL is in agreement with the loss of a majority of alkalis put in evidence by EDX. Note that these findings are also consistent with the TGA results: in Aand P-altered powders, the mass loss occurs progressively on a wide temperature range (essentially $\left[225-550^{\circ} \mathrm{C}\right]$ ) because of the distribution of $\mathrm{H}$-bonding strengths with the silanols strongly bound to NBOs escaping at higher temperature, while in the SLaltered powder, the majority of the mass loss is due to weakly bound molecular $\mathrm{H}_{2} \mathrm{O}$ and occurs below $225^{\circ} \mathrm{C}$.

The ${ }^{29} \mathrm{Si}$ MAS NMR spectra of the altered glass powders are shown in Fig. 9. The ${ }^{29}$ Si MAS NMR spectra of the pristine glasses are depicted with a black line, and the attribution in terms of $Q^{n}$ species $\left(\mathrm{SiO}_{4}\right.$ units bearing $\mathrm{n}$-brigding oxygens, $\left.\mathrm{BO}\right)$ is shown as a green mark in the figure. The chemical shifts and the integrated intensities of the $\mathrm{Q}^{\mathrm{n}}$ components of the pristine glasses are consistent with the glass composition (Table 1) and the literature ${ }^{21}$. The silicate networks of glasses $P$ and $A(N B O / S i=$ 0.44 and 0.66 , respectively) are mainly composed of $Q^{4}$ and $Q^{3}$ species, while the silicate network of glass $\mathrm{SL}(\mathrm{NBO} / \mathrm{Si}=0.90)$ is mainly composed of $\mathrm{Q}^{3}$ species. After the ageing at $40^{\circ} \mathrm{C}, 85 \mathrm{RH} \%$ for 6 months, the $Q^{4}$ component has markedly decreased for glasses $A$ and $P$ (MAS spectra in pink in Fig. $9 a, b$ ), and the $Q^{3}$ and $\mathrm{Q}^{2}$ components have raised. These glasses have been therefore depolymerized with the hydration. On the contrary, the spectrum of the SL-hydrated layer (pink line in Fig. 9c) has considerably changed with a greater intensity in the region of the $Q^{4}$ species at the expense of the $Q^{3}$ and $Q^{2}$ species. The hydrated layer of this 

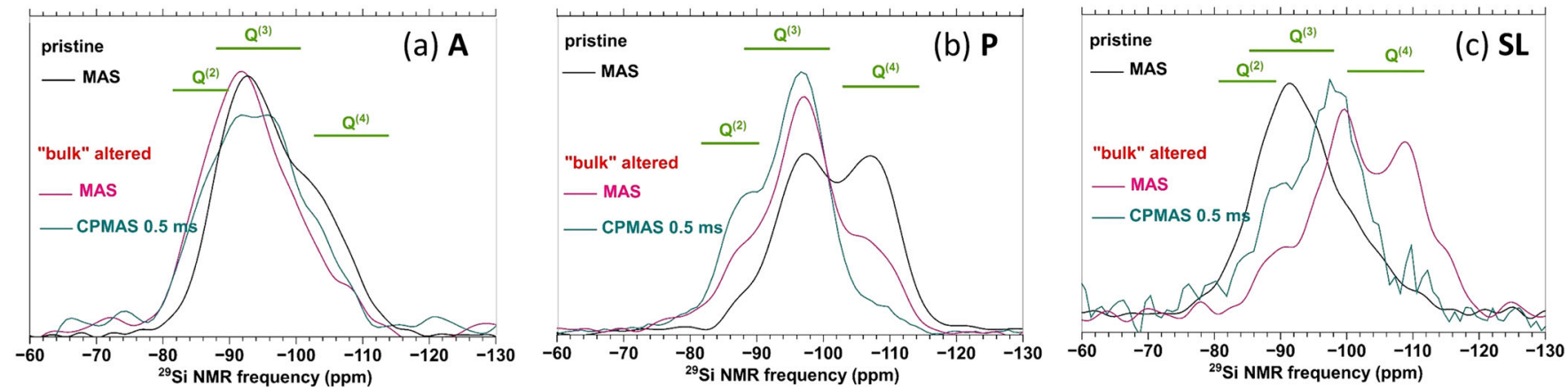

Fig. $9{ }^{29}$ Si MAS and CPMAS NMR spectra of pristine and aged glass powders. ${ }^{29} \mathrm{Si}$ MAS and CPMAS ${ }^{1} \mathrm{H} \rightarrow{ }^{29} \mathrm{Si}$ NMR spectra of pristine and bulk altered powders after an ageing test at $40^{\circ} \mathrm{C}, 85 \mathrm{RH} \%, 6$ months (hermetic box containing a saline solution of $\mathrm{KCl}$ in $\mathrm{H}_{2} \mathrm{O}$ ). The spectra are normalized to the same area. a Glass A; b glass P; c glass SL.
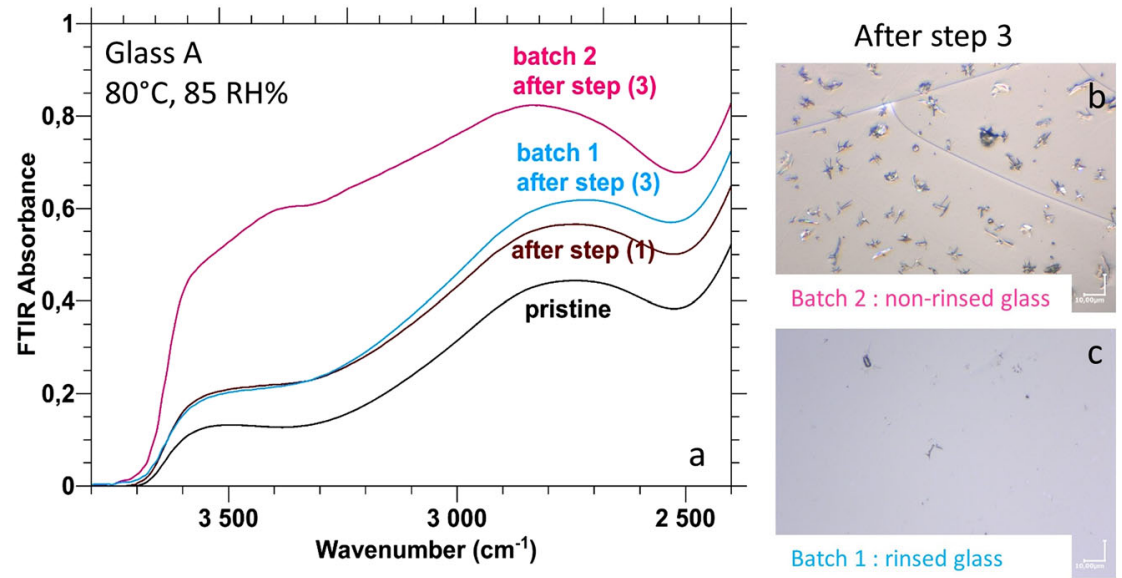

Fig. 10 Results obtained by rinsing the alteration layer before a second period of accelerated ageing (called step 3). a. Transmission FTIR spectra obtained from pristine and aged glass plates A (ageing at $80^{\circ} \mathrm{C}, 85 \mathrm{RH} \%$ ). Step (1): 18-h ageing, Step (3): $24-\mathrm{h}$ ageing, Batch 1: rinsed, Batch 2, non-rinsed. Optical microscopy images of these plates are shown in $\mathbf{b}$ (batch 2) and $\mathbf{c}$ (batch 1 ). The scale bar is $10 \mu \mathrm{m}$.

glass is clearly distinct of the pristine glass and markedly polymerized. The ${ }^{1} \mathrm{H} \rightarrow{ }^{29} \mathrm{Si}$ CPMAS spectra of the altered powders are also shown in Fig. 9 as a blue line. They expectedly indicate that the $Q^{4}$ species are the most distant of the protons, because the intensity of the $\mathrm{Q}^{4}$ component has decreased.

\section{Additional experiments}

The results described above suggest a correlation between the retention of alkalis in the hydrated layer (high for $\mathrm{A}$ and $\mathrm{P}$ glasses, low for SL glass) and the chemical durability with respect to atmospheric humidity (low for $\mathrm{A}$ and $\mathrm{P}$, high for $\mathrm{SL}$ ). The high basicity of hydrated layers containing NBOs and alkalis, having a catalytic effect on the network hydrolysis, could provide a chemical basis to explain such a correlation. In order to test this hypothesis, we performed experiments consisting of rinsing the aged glass plates for a short time in ultrapure liquid water at room temperature.

These experiments were conducted on two batches of glass plates of the same composition, at both temperatures $\left(40^{\circ} \mathrm{C}\right.$ and $80^{\circ} \mathrm{C}$ ) for glass composition $\mathrm{A}$ and at $40^{\circ} \mathrm{C}$ only for glass compositions $\mathrm{P}$ and SL. They comprise three steps that are detailed here for the ageing temperature of $80^{\circ} \mathrm{C}$ : (1) Pre-ageing of the two batches at $80^{\circ} \mathrm{C}, 85 \mathrm{RH} \%$ during $18 \mathrm{~h}$ (noted P18h test); (2) immediately after the P18h test (time $t_{1}$ ), batch 1 is immersed in milliQ water at room temperature during $5 \mathrm{~min}$, then carefully dried under air flux $\left(T<40^{\circ} \mathrm{C}\right)$ and then stored in ambient atmosphere during 1 day. Batch 2 is stored in ambient atmosphere during 1 day from time $t_{1}$, without any rinsing, to serve as a reference; (3) the two batches are aged for $24 \mathrm{~h}$ at $80^{\circ} \mathrm{C}, 85 \mathrm{RH} \%$. For the ageing temperature of $40^{\circ} \mathrm{C}$, the pre-ageing duration (step 1 ) was 17 days or 3 months, and the ageing duration (step 3) was 22 days or 6 months (respectively).

In the following, the results obtained with the experiment at $80^{\circ} \mathrm{C}$ on glass $\mathrm{A}$ are detailed. Notably, the rinsing operation in step (2) caused the removal of a limited fraction of alkalis out of the alteration layer as shown by ICP-AES analysis of the rinsing water ( 20 and $10 \%$ of $\mathrm{Na}^{+}$and $\mathrm{K}^{+}$ions, respectively, are extracted from the hydrated layer $\left.{ }^{14}\right)$. At the end of step (3), the surface states of batch 1 (rinsed) appeared far less altered on the macroscopic scale, with no visible cracks and a limited quantity of alteration salts, as compared with batch 2 (non-rinsed). The reduction of the macroscopic manifestations suggests a benefit of the rinsing step on the reduction of the glass hydration kinetics, which was followed by transmission FTIR. In Fig. 10, we observe an increase of the absorbance band associated to the -OH groups after step (1) (brown curve compared to black curve), which confirms the hydration of the glass surface during the pre-ageing step. After step (3), the absorbance of batch 2 (pink curve) is significantly higher: hydration had resumed, following an accelerating kinetics that was reported and discussed in ref. ${ }^{14}$. Remarkably, the signal of batch 1 is in contrast almost unchanged after step (3) (blue curve compared to brown curve): the rinsing step seems to have almost stopped the alteration in our experimental conditions.

A reduction of the alteration kinetics at $40{ }^{\circ} \mathrm{C}$ (over 3 months of ageing) after a rinsing step of the alteration layers has also been observed for the 3 glass replicas. This was obvious 
macroscopically, with the reduction of the surface amount of salts and, for both glasses $A$ and $P$, the suppression of the crizzling. This was confirmed at a microscopic scale for the glass SL by ToF-SIMS depth profiling (not shown), with the reduction of the hydratedlayer thickness from $\sim 300 \mathrm{~nm}$ (batch 2) to less than $200 \mathrm{~nm}$ (batch 1). These experiments thus confirmed our guess that the removal of a fraction of alkalis from the hydrated layers would lead to a reduction of the hydration kinetics.

\section{DISCUSSION}

The alteration of three glass replicas has been carried out in controlled conditions of unsaturated humidity (85 RH\%) and temperature $\left(40^{\circ} \mathrm{C}\right.$ and $\left.80^{\circ} \mathrm{C}\right)$. Out of these three glass compositions, two are known as «unstable» and one as "stable» in the cultural heritage field, and this empirical knowledge has been verified in our accelerated ageing experiments. The study clearly shows distinct experimental results for the two groups of glasses. In the unstable $A$ and $P$ glass compositions, the hydrated layer retains a high proportion of alkalis still bonded to the NBOs. The silicate network is depolymerized, bearing $\mathrm{NBO}$ s and $\mathrm{Si}-\mathrm{OH}$ groups in a dense network of $\mathrm{H}$ bonds. In these two compositions, the hydrolysis of the silicate network is obviously the fastest process of glass hydration, inducing the depolymerization. The stable SL glass composition has a very different behaviour. The hydrated layer is composed of two sub-layers: an external sublayer that corresponds to the alteration products after the complete transformation of the hydrated glass, and an internal sub-layer that is the hydrated glass. Thus, in this glass composition, after a short step of hydration, the hydrated glass fully decomposes into alkali salts and polymerized silica. This process considerably slows down the overall glass hydration: the alteration layer of this glass is very much smaller than for the other two glasses, at all times and temperatures. In this section, we first discuss the new insight provided by these results with respect to the literature, then we draw hypotheses to relate the composition and structure of the hydrated layers to the glass chemical durability in atmosphere, which may inspire future research to address the effect of the glass composition.

To the best of our knowledge, ${ }^{1} \mathrm{H}$ and ${ }^{29} \mathrm{Si}$ MAS NMR had never been used to investigate the structure of the glass-hydrated layers produced in atmospheric conditions. If many studies in the literature have noticed that alkalis were partially or totally retained in these hydrated layers (see a review in ref. ${ }^{22}$ ), none could state about the existence of NBOs because of lack of structural data. The high ${ }^{1} \mathrm{H}$ chemical shifts in the ${ }^{1} \mathrm{H}$ NMR MAS spectra are attributable only to protons $\mathrm{H}$-bound to NBOs, according to the correlation between ${ }^{1} \mathrm{H}$ NMR chemical shift and $\mathrm{H}$-bonding strength well known in the literature (see the discussion in refs. ${ }^{15,16}$ for instance).

The existence of NBOs tells us that a fraction of "Si-O-Na,K" sites are not dissociated in the hydrated layer, with probable consequences on the stability of the interface with the pristine glass as discussed later. This is a new insight, because in the literature, studies about glass atmospheric alteration tend to consider that the retained alkalis are released in the poral water of the hydrated layer, and do not migrate to the surface because of the cancellation of the chemical gradient due to the saturation of alkalis in the surface water film ${ }^{23,24}$.

Another insight provided by this study is related to the question "does the precipitation of carbonate salts on the surface control the kinetics of the alteration process?" To our sense, the surface precipitation of these salts is a secondary process. It happens when the alkalis are entirely solvated and able to migrate to the surface (driven by the chemical gradient due to salt precipitation). But this study demonstrates that depending on the composition, many alkalis can stay bound to their NBOs, which does not stop the alteration. On the contrary, alteration seems to go faster when alkalis stay next to their NBOs (case of A and P compared to SL). It is the proof that the precipitation of salts is not necessary for the alteration, it is a secondary process. We had discussed this observation in detail in ref. ${ }^{14}$, where the glass $\mathrm{A}$ hydrated fast and dramatically without any formation of surface salts (at $80^{\circ} \mathrm{C}$ and $85 \mathrm{RH} \%$ ). Note that the precipitation of silicate phases, generally phyllosilicates, enhances the alteration kinetics. This precipitation occurs at high $\mathrm{pH}$ or high $T$ in aqueous medium ${ }^{25}$, and at high $T$ in atmosphere ${ }^{26}$, or at moderate $T$ in atmosphere for aluminosilicate compositions such as the Mg-, Al-enriched AVM glasses in ref. ${ }^{23}$. However, the precipitation of alkali-carbonate salts does not seem to influence the alteration kinetics. Possibly, it is because the passivation potential of the hydrated silicate layer is preserved, as these salts do not provide any sink for $\mathrm{Si}$.

On the other hand, the alkalis and NBO retention seems to play a role in the alteration kinetics. It is possible to draw hypothesis to explain the contrasted chemical durability, based on the composition of the hydrated layers highlighted in this study. In the $A$ and $P$ glass compositions, which strongly stabilize alkalis and NBOs in their hydrated layer, the hydrated layer is basic in a chemical Lewis sense. Incoming water molecules may be dissociated onto NBO sites, which catalyze the network hydrolysis $^{14}$ :

$$
\begin{aligned}
& \mathrm{Si}-\mathrm{O}-\mathrm{Na}+\mathrm{H}_{2} \mathrm{O} \leftrightarrow \mathrm{Si}-\mathrm{OH}+\mathrm{Na}^{+}+\mathrm{OH}^{-} \\
& \mathrm{Si}-\mathrm{O}-\mathrm{Si}+\mathrm{OH}^{-} \leftrightarrow \mathrm{Si}-\mathrm{OH}+\mathrm{Si}-\mathrm{O}^{-} \\
& \mathrm{Si}-\mathrm{O}^{-}+\mathrm{Na}^{+} \leftrightarrow \mathrm{Si}-\mathrm{O}-\mathrm{Na}
\end{aligned}
$$

The outcome is then $((1)+(2)+(3))$

$\mathrm{Si}-\mathrm{O}-\mathrm{Si}+\mathrm{H}_{2} \mathrm{O} \leftrightarrow 2 \mathrm{Si}-\mathrm{OH}$

with the "Si - $\mathrm{O}-\mathrm{Na}$ " species playing a catalytic role. Fast $\mathrm{Si}-\mathrm{O}-\mathrm{Si}$ hydrolysis (reaction (2)) is promoted because $\mathrm{OH}^{-}$is a better nucleophile than $\mathrm{H}_{2} \mathrm{O}$. The hydration progresses as long as new water molecules are provided by the humid atmosphere.

The ageing experiments with an intermediate rinsing step support this hypothesis. During the rinsing step, a fraction of alkalis is extracted to the rinsing solution, together with $\mathrm{OH}^{-}$or by ionic exchange with $\mathrm{H}^{+}$ions from the water. Consequently, the hydrated layer is (partially) neutralized in a chemical sense, which probably slows down the network hydrolysis at the interface with the pristine glass. As a matter of fact, the resumption of the hydration is reduced after this rinsing step.

In this discussion, we intentionally use the general term of Lewis basicity, which does not refer to any solvent and can be used for solids, instead of "local $\mathrm{pH}^{\text {". }}$ The $\mathrm{pH}$ refers to aqueous conditions since it is defined as the (opposite of the logarithm of) concentration of $\mathrm{H}^{+}$in liquid water. We prefer a more general term because we think that in atmospheric alteration at least in the first stage, water is a reactant, but it cannot be considered as a solvent. In a later stage, it is probable that the capillary condensation of water in the nanoporosity opened by network depolymerization and departure of alkali and alkaline-earth ions changes this situation, with the apparition of a true liquid phase and local pH conditions as put forward in ref. ${ }^{27}$ for instance.

In the SL glass composition, the hydrated layer does not seem to retain for a long time the alkalis. After reaction (1), the alkalis and their counterions $\mathrm{OH}^{-}$are able to migrate to the surface and precipitate with $\mathrm{CO}_{2}$ to form carbonate salts (or $\mathrm{SO}_{3}$ for sulfates), for instance:

$\mathrm{Na}^{+}+\mathrm{OH}^{-}+\mathrm{CO}_{2} \leftrightarrow \mathrm{NaHCO}_{3}$

$2 \mathrm{Na}^{+}+2 \mathrm{OH}^{-}+\mathrm{CO}_{2} \leftrightarrow \mathrm{Na}_{2} \mathrm{CO}_{3}+\mathrm{H}_{2} \mathrm{O}$.

This means that these ions could be efficiently solvated in the hydrated layer (we assume that unsolvated cations stay bound to the NBOs and are not mobile). The salt precipitation neutralizes 
this layer in a Lewis sense. The dealkalized hydrated layer appears fully destabilized and transforms into polymerized silica, either by dissolution-precipitation, or by in situ condensation. It is possible that both the departure of cations $\left(\mathrm{Na}^{+}\right.$and $\left.\mathrm{Ca}^{2+}\right)$ and the transformation of NBOs into silanols induce a collapse of the dense $\mathrm{H}$-bonding network that ensured the stability of the hydrated layer in A and $\mathrm{P}$ compositions. As we can experimentally observe, this process considerably slows down the hydration kinetics at the interface with the pristine glass.

Following these hypotheses, although the contrasted chemical durability may possibly be explained based on this notion of basicity of the hydrated layer, many questions arise, so that the influence of the glass composition largely stays misunderstood. Why do the $A$ and $P$ glass compositions retain the alkalis and NBOs, and not the SL composition? This is probably one of the fundamental questions and we have no clues to answer, neither are we able to highlight any relevant compositional parameter. Table 1 shows the glass compositions and two compositional parameters: the depolymerization ratio $\mathrm{NBO} / \mathrm{Si}$, and the ratio of alkaline-earth oxides over $\mathrm{SiO}_{2}$. Glass $\mathrm{SL}$ has a lower $\mathrm{SiO}_{2}$ content and a higher NBO/Si ratio than the other two glasses. Could it be related to its weaker ability to retain the alkalis? Glass SL has a higher ratio of alkaline-earth oxides over $\mathrm{SiO}_{2}$ also: does it affect this retention factor as well? Considering this latter parameter, we think that it may be an important clue, maybe underlying the wellknown stabilization effect of the alkaline-earth oxides. The behaviour of the $\mathrm{Ca}^{2+}$ ions is noticeable in the experiments of this study: in the A and SL glass compositions, they fully migrate to the surface to precipitate as carbonates (mainly calcite). Note that this strikingly high mobility of $\mathrm{Ca}^{2+}$ ions was noticed in a very comprehensive study of the atmospheric alteration of an industrial soda-lime silicate glass ${ }^{28}$. On the contrary, in the $P$ composition, they are retained in the hydrated layer, except in the near surface where they precipitate as carbonates (see Table 3 and Fig. 7). What may explain this differentiated behaviour? At first, it is interesting to notice the order of retention of the three modifier cations: $\mathrm{Na}^{+}, \mathrm{K}^{+}$and $\mathrm{Ca}^{2+}$, in the hydrated layer. In $\mathrm{A}$ and $\mathrm{SL}$ glasses, it is clearly $\mathrm{K}^{+}>\mathrm{Na}^{+}$» $\mathrm{Ca}^{2+}$ (Table 3 and Fig. 7). Such an order has been discussed in a previous paper ${ }^{15}$. Following studies of ionic exchange in glass- alteration gels in the literature ${ }^{29}$, we suggest that the cations are retained in the hydrated layer in the reverse order of their hydration enthalpy. $\mathrm{Ca}^{2+}$ ions are strongly stabilized by hydration; they are thus more quantitatively solvated and released from the hydrated layer. In contrast, $\mathrm{K}^{+}$ions are "hydrophobic" cations that are weakly stabilized by hydration and prefer staying bound to their NBOs. In glass $\mathrm{P}$, the $\mathrm{Ca}^{2+}$ cations are however not much released (except near the surface). This composition is very rich in $\mathrm{K}_{2} \mathrm{O}$, so that $\mathrm{K}^{+}$ions dominate the chemical and structural properties of the hydrated layer: we propose that because of their presence, there is less water in this hydrated glass, which would hamper efficient $\mathrm{Ca}^{2+}$ hydration. In addition, the big $\mathrm{K}^{+}$alkali may obstruct the migration paths of the solvated $\mathrm{Ca}^{2+}$ ions. These considerations made, we come back to the influence of the $(\mathrm{CaO}+\mathrm{MgO}) / \mathrm{SiO}_{2}$ ratio on the chemical durability. It is possible that because $\mathrm{Ca}^{2+}$ ions (and $\mathrm{Mg}^{2+}$ ions as observed in the TOF-SIMS profile of the aged SL glass, Fig. 7a) are quantitatively released from the hydrated glass (together with $\mathrm{OH}^{-}$ions or by ionic exchange with $\mathrm{H}^{+}$), they contribute to more rapidly neutralize the hydrated layer, which stabilizes the interface with the pristine glass and slows down the hydration as discussed above. Again, these speculative considerations are to be taken with caution, because all the other oxide ratios change a little between the three glasses. For instance, the $\mathrm{Al}_{2} \mathrm{O}_{3}$ molar content in the SL composition is three times superior to the content in $\mathrm{A}$ and $P$, which certainly also plays a role in the chemical durability, as for instance demonstrated in ref. ${ }^{30}$ among many other studies.

The $(\mathrm{CaO}+\mathrm{MgO}) / \mathrm{SiO}_{2}$ ratio, as well as the $\mathrm{NBO} / \mathrm{Si}$ ratio, also have an impact on the network structure and oxygen-packing density, which modifies the number of chemical topological constraints per atom in the glass. This latter parameter correlates with the glass dissolution rate as it was recently demonstrated for a wide range of glass compositions and $\mathrm{pH}$ conditions ${ }^{31}$. The higher the number of topological constraints per atom, the higher the activation energy for bond hydrolysis due to topological hindrance effects. We think that these topological effects, as well as possibly the mixed-cation ordering in glasses and the associated mixed-alkali effects ${ }^{32}$, probably also play a role in the alkali-retention/-solvation properties and their mobility in the hydrated layers.

At last, it is interesting to notice that the content in alkalineearth oxide, namely $\mathrm{MgO}$, and the $\mathrm{MgO} / \mathrm{Al}_{2} \mathrm{O}_{3}$ ratio were pointed out as a possible compositional parameter controlling the alteration kinetics of aluminoborosilicate glasses in atmospheric conditions ${ }^{23}$. The origin of this effect lies in the dual role of $\mathrm{Mg}^{2+}$ cations in the alteration layer: these ions may become charge compensator of $\mathrm{AlO}_{4}$ units, with a positive effect on slowing down the kinetics, or they can drive $\mathrm{Mg}$-smectite precipitation, with a negative effect. For these multicomponent glasses, the chemistry of the hydrated layer is more complex than that of the alkali and alkaline-earth silicate glasses of this study.

To confirm the hypotheses and "guesses" about the composition effect on the glass chemical durability, dedicated studies are necessary with glass compositions varying in a systematic way, for instance the $\mathrm{CaO} / \mathrm{SiO}_{2}$ ratio in $\mathrm{SL}$ glasses. The quantification of all hydrated species in the hydrated layer are important perspectives to better understand the hydrated-layer chemistry. ${ }^{1} \mathrm{H}$ MAS NMR associated with TGA provides this possibility ${ }^{33}$. What is the role of the $\mathrm{H}$-bond strength distribution on the hydrated-layer properties? Are there indeed more water molecules in a sodium-rich hydrated layer than in a potassium-rich hydrated layer, as suggested here? At last, are these findings about the compositional effects specific to the glass alteration in atmospheric conditions $(\mathrm{RH}<100 \%)$ ? The specificities of the glass atmospheric alteration have been discussed elsewhere ${ }^{22}$, they mainly lie in the bound state of nearly all the water molecules, which thus lose in part their solvating properties. This may possibly amplify the compositional effects, leading to the large behavioural differences highlighted in this paper, although it remains to be demonstrated.

At last, a deeper insight into the influence of the glass composition on the atmospheric glass alteration will help adapting and improving the methods of glass conservation in the cultural heritage field. In this regard, the experiments with a rinsing step introduced in this study are encouraging, and even more so because many curators already carry out regular cleaning of unstable glass objects to remove the surface salts, using water, water-alcohol solution or slightly acidic solutions ${ }^{1,2,4}$. More chemical studies would provide a scientific basis to improve and consolidate these simple protective treatments of our cultural heritage.

\section{METHODS}

\section{Sample preparation}

The three glass replicas were fabricated by Saint-Gobain Recherche (France) by melting the mixture of reagent-grade powders at $1450^{\circ} \mathrm{C}$ for $2 \mathrm{~h}$, annealing the casted block at $560^{\circ} \mathrm{C}$ and then cooling down slowly for $1 \mathrm{~h}$ to relieve stresses and enable cutting.

Samples were prepared in the form of polished plates $\left(1 \times 1 \times 0.3 \mathrm{~cm}^{3}\right)$, which were cleaned shortly before the ageing tests, according to the procedure described in ref. ${ }^{14}$. For NMR spectroscopy, calibrated glass powders (32-50- $\mu \mathrm{m}, 5-10-\mu \mathrm{m}$ and $2-5-\mu \mathrm{m}$ size fractions) were prepared and thoroughly washed under ethanol and acetone ${ }^{14}$. Their specific surface area was measured by the BET method, using a Belsorp Max analyzer with krypton as adsorbing gas. The size homogeneity of the glass particles was checked under an optical or an electronic microscope. 


\section{Ageing tests}

Two different devices were used in parallel to control simultaneously the relative humidity and the temperature of the ageing atmosphere over various time periods (from some hours to several months): (i) a climatic chamber and (ii) a hermetic box put in an oven and containing a saturated $\mathrm{KCl}$ solution $^{34}$. The ageing tests were performed in static mode (no cycling), and the climatic conditions $\left(T^{\circ} \mathrm{C}\right.$ and $\left.\mathrm{RH} \%\right)$ were chosen to avoid any liquid water run-off onto the samples. Every ageing test conducted with the device (i) begun with a heating ramp of $3 \mathrm{~h}$ from ambient conditions $\left(20^{\circ} \mathrm{C}, 35 \% \mathrm{RH}\right)$ until the dwell $\left(85 \mathrm{RH} \%\right.$ and $40^{\circ} \mathrm{C}$ or $\left.80^{\circ} \mathrm{C}\right)$, and ended with a cooling ramp of $3 \mathrm{~h}$ until ambient conditions. The device (ii) was used exclusively for ageing tests at $85 \% \mathrm{RH}$ and $40{ }^{\circ} \mathrm{C}$, over several weeks or several months. A MadgeTech data logger was inserted inside the box to register the $T$ and $\mathrm{RH}$ conditions. The hermetic box containing the samples was put in the preheated oven before the thermodynamic equilibrium of the three phases (solid salt-liquid water-air/water vapour), which takes place in about 1 day. At the end of the ageing test, the hermetic box was removed from the oven and immediately opened in order to avoid condensation onto the samples. Note that the equivalence between the two ageing methods (with device (i) or (ii)) had been checked by comparison of a 2 -month ageing test at $50{ }^{\circ} \mathrm{C}, 85 \% \mathrm{RH}$, for the three glass replicas.

Just after their removal from the ageing device, the aged glass plates were put in the atmosphere of the laboratory at room temperature. The $T$ and $\mathrm{RH} \%$ variations in the laboratory were measured with a MadgeTech data logger (average temperature: $22.2^{\circ} \mathrm{C}$; average $\mathrm{RH}: 36.2 \%$ ). The aged glass powders were kept in Eppendorf tubes stored in desiccators until their characterization, to limit interaction with the atmosphere.

\section{Characterization methods}

Sample preparation before the characterizations was very limited. Notably, no rinsing or polishing was performed.

The surface states of the glass plates were characterized before the ageing tests and several times after the ageing tests by means of a binocular magnifier and an optical microscope equipped with a camera Nikon DS-3, or with a numerical microscope Keyence VHX-5000 in direct or grazing light. This characterization was supplemented by observations with an electronic microscope FEG-SEM JEOL $7800 \mathrm{~F}$, preferentially in secondary electron mode at low acceleration tension (2-7 kV), after making the glass surface conductive with a platinum deposit of about 1-nm thick. For the platinum- layer deposition and the SEM observation, samples were submitted to a vacuum of about $1 \mathrm{~Pa}$ and $5 \cdot 10^{-5} \mathrm{~Pa}$, respectively.

STEM observations of the edge of certain aged glass plates of the SL composition were carried out with a TEM microscope JEOL2100F at $200 \mathrm{kV}$, with a very low current because the alteration layers were unstable under the electronic beam.

The alteration layer thickness was determined from the depth profiles obtained at the surface of the aged glass plates by Tof-SIMS analysis, only when it was below about $200 \mathrm{~nm}$. To this end, we considered the distance over which the ${ }^{45} \mathrm{SiOH}^{+} /{ }^{28} \mathrm{Si}^{+}$ratio is halfway between its surface and its baseline concentration as a marker of the interface between the hydrated layer and the pristine glass, by analogy with a method described in ref. ${ }^{35}$ using the ${ }^{1} \mathrm{H}^{+} /{ }^{28} \mathrm{Si}^{+}$ratio. ToF-SIMS analyses were carried out on a Tof-SIMS V instrument (Ion-Tof company), using a $\mathrm{O}_{2}{ }^{+}$ion beam $(2 \mathrm{keV}, \sim 150 \mathrm{nA})$ for in-depth abrasion, $\mathrm{a} \mathrm{Bi}^{+}$ion beam $(25 \mathrm{keV}, 0.3 \mathrm{pA})$ for the analysis and an unfocused electron beam of some $\mathrm{eV}$ for the charge neutralization. The crater was $200 \times 200 \mu \mathrm{m}$ or $300 \times 300 \mu \mathrm{m}$ in size, and at its centre, the analysis zone was $50 \times 50 \mu \mathrm{m}$ or $100 \times 100 \mu \mathrm{m}$, respectively. The sputtering rate was determined on aged glass plates with mechanical profilometry $(\sim 0.34 \mathrm{~nm} / \mathrm{s}$ into the altered layer for a current of $100 \mathrm{nA}$ ).

When the alteration layer thickness was higher than about $200 \mathrm{~nm}$, it was measured with the FEG-SEM. When flakes formed on the glass plates, their thickness was measured and associated to the alteration layer thickness because the flaking occurred at the interface between the alteration layer and the pristine glass (the composition of the glass below the flakes was identical to the composition of the pristine glass, as measured by EDX). Otherwise, SEM observations were performed on the edge, on a freshly fractured sample, preferentially in backscattered electron mode to visualize the chemical contrast at the interface-altered layer-pristine glass. These observations were performed in different areas of the same aged glass plate and we give an average thickness $e_{a}$.

Chemical compositions of the alteration layers were measured by EDX with the system Bruker QUANTAX 400, at the same time as SEM observations. Analyses were performed on the glass plate surface, outside any defect or crystal, according to the operating conditions and the specific quantification method described in ref. ${ }^{14}$. In particular, for the quantification with the STRATAGem data-processing software, glass plates were modelled as stacks of several layers of known thickness: alteration layer/Pt or pristine glass/alteration layer/Pt when the alteration layer thickness was smaller than the analyzed depth.

Chemical depth profiles were obtained by Tof-SIMS analysis as described above.

Chemical characterization of the alteration products on the surface of glass plates was performed by EDX at low acceleration tension, by XRD with a X'Pert PRO PANalytical instrument using Cu-Ka radiation and by micro-Raman spectroscopy with a Renishaw Invia spectrometer using a 532-nm solid-state laser as excitation light.

The water content in the hydrated layer, or hydration rate, was measured on glass plates by EDX according to the original method described in ref. ${ }^{14}$. This local measurement corresponds to the water content that has not been evaporated under vacuum, i.e., to the tightly bound water. For comparison, weight loss measurements of aged glass powders by TGA analysis were performed with a NETZCH STA449 F3 Jupiter equipment, considering that the tightly bound water disappears between about 150 and $500^{\circ} \mathrm{C}$. About $150 \mathrm{mg}$ of powder was put in an alumina crucible and heated from $20^{\circ} \mathrm{C}$ to $900^{\circ} \mathrm{C}$ at $10^{\circ} \mathrm{C} / \mathrm{min}$, then cooled to room temperature with the same rate, under nitrogen flux. The TGA measurements were corrected for a baseline that was separately measured using an empty crucible.

FTIR spectroscopy in transmission mode was used to compare the hydration rate of different glass plates. The spectra were recorded with a Bruker Tensor27 FTIR spectrometer in the range $4000-2200 \mathrm{~cm}^{-1}$, using a resolution of $10 \mathrm{~cm}^{-1}, 100$ sample scans and 100 background scans.

${ }^{1} \mathrm{H}$ and ${ }^{29}$ Si magic-angle spinning (MAS) NMR spectra of the aged glass powders were collected with Bruker Avance I and Avance II spectrometers operating at magnetic fields of $7.02 \mathrm{~T}$ (300WB) and 11.72 T (500WB), respectively. For these experiments, about $100 \mathrm{mg}$ of powder was packed in 4-mm outer-diameter $\mathrm{ZrO}_{2}$ rotor, and spun from $10 \mathrm{kHz}(7.02 \mathrm{~T})$ to $12.5 \mathrm{kHz}(11.72 \mathrm{~T})$ using Bruker CPMAS probes. The recycle delay applied for the complete relaxation of nuclear magnetizations was about $1 \mathrm{~s}$ for ${ }^{1} \mathrm{H}$, and from 20 to $200 \mathrm{~s}$ for the ${ }^{29} \mathrm{Si}$ nucleus. ${ }^{1} \mathrm{H}$ spectra were acquired using the Hahn echo-pulse sequence $\left(90-\mathrm{T}_{\mathrm{E}}-180-\mathrm{T}_{\mathrm{E}}-\mathrm{Acq}\right)$ with a rotorsynchronized echo delay $\mathrm{T}_{\mathrm{E}}$. The ${ }^{29} \mathrm{Si}$ MAS spectra were recorded using the CPMG sequence to reduce the times of acquisition to a few tens of seconds. ${ }^{29} \mathrm{Si}$ cross-polarization (CP)-MAS experiments (polarization transfer ${ }^{1} \mathrm{H} \rightarrow{ }^{29} \mathrm{Si}$ ) were performed with contact times of $0.5 \mathrm{~ms}$.

In this paper, we employ the $Q^{n}$ notation, where $n$ is the number of bridging oxygens on the $\mathrm{SiO}_{4}$ tetrahedron $\mathrm{Q}$, to describe the structure of the silicate network at short distance.

\section{DATA AVAILABILITY}

The data that support the findings of this study are available from the corresponding author upon reasonable request.

Received: 18 May 2020; Accepted: 17 October 2020; Published online: 12 November 2020

\section{REFERENCES}

1. Davison, S. \& Newton, R. G. Conservation and Restauration of Glass (Elservier, 2003).

2. Koob, S. P. Conservation and Care of Glass Objects (Archetype Publications, 2006).

3. Organ, R. M. The safe storage of unstable glass. Mus. J. 56, 255-272 (1957).

4. Kunicki-Goldfinger, J. J. Unstable historic glass: symptoms, causes, mechanisms and conservation. Rev. Conserv. 9, 47-60 (2008).

5. Glass Atmospheric Alteration - Cultural Heritage, Industrial and Nuclear Glasses (Eds Biron, I., Alloteau, F., Lehuédé, P., Majérus, O., Caurant, D.) (Hermann, 2019).

6. Brill, R. H. Crizzling-a problem in glass conservation. Stud. Conserv. 20, 121-134 (1975).

7. Koob, S. P. Crizzling glasses: problems and solutions. Eur. J. Glas. Sci. Technol. A 53, 225-227 (2012).

8. Léang, M., Giorgiutti-Dauphiné, F., Lee, L. T. \& Pauchard, L. Crack opening: from colloidal systems to paintings. Soft Matter 13, 5802-5808 (2017).

9. Lahlil, S., Xu, J. \& Li, W. Influence of manufacturing parameters on the crackling process of ancient Chinese glazed ceramics. J. Cult. Herit. 16, 401-412 (2015). 
10. Verità, M. Venetian soda glass. in Modern Methods fo Analysing Archeological and Historical Glass (ed. Janssens, K.) 515-533 (John Wiley \& Sons, 2013).

11. Melcher, M. \& Schreiner, M. Leaching studies on naturally weathered potashlime-silica glasses. J. Non Cryst. Solids 352, 368-379 (2006).

12. Iliffe, C. J. \& Newton, R. G. Using triangular diagrams to understand the behaviour of medieval glasses. Verres Refract 30, 30-34 (1976).

13. Biron, I. Le matériau verre et les objets du patrimoine. Origine et manifestation des problèmes rencontrés. in Conservation, restauration du verre. Actualité et problématiques muséales - Trélon 28 septembre 2007 13-23 (Écomusée de I'Avesnois, 2007).

14. Alloteau, F. et al. New insight into atmospheric alteration of alkali-lime silicate glasses. Corros. Sci. 122, 12-25 (2017).

15. Alloteau, F. et al. Temperature-dependent mechanisms of the atmospheric alteration of a mixed-alkali lime silicate glass. Corros. Sci. 159, 108129 (2019).

16. Xue, X. \& Kanzaki, M. Proton distributions and hydrogen bonding in crystalline and glassy hydrous silicates and related inorganic materials: insights from highresolution solid-state nuclear magnetic resonance spectroscopy. J. Am. Ceram. Soc. 92, 2803-2830 (2009).

17. Xue, X. \& Kanzaki, M. Dissolution mechanisms of water in depolymerized silicate melts: constraints from $1 \mathrm{H}$ and29Si NMR spectroscopy and ab initio calculations. Geochim. Cosmochim. Acta 68, 5027-5057 (2004).

18. Le Losq, C., Cody, G. D. \& Mysen, B. O. Alkali influence on the water speciation and the environment of protons in silicate glasses revealed by $1 \mathrm{H}$ MAS NMR spectroscopy. Am. Mineral. 100, 466-473 (2015).

19. Angéli, F., Gaillard, M., Jollivet, P. \& Charpentier, T. Influence of glass composition and alteration solution on leached silicate glass structure: a solid-state NMR investigation. Geochim. Cosmochim. Acta 70, 2577-2590 (2006).

20. $\mathrm{Ai}, \mathrm{X}$. et al. One- and two-dimensional solid-state magic angle spinning NMR studies on the hydration process of layered sodium disilicate SKS-6. Solid State Nucl. Magn. Reson. 25, 216-226 (2004).

21. Maekawa, H., Maekawa, T., Kawamura, K. \& Yokokawa, T. The structural groups of alkali silicate glasses determined from 29Si NMR. J. Non Cryst. Solids 127, 53-64 (1991).

22. Majérus, O. et al. Glass alteration in atmospheric conditions: crossing perspectives from cultural heritage, glass industry and nuclear waste management. npj Mater. Degrad. 4, 1-16 (2020).

23. Narayanasamy, S. et al. Influence of composition of nuclear waste glasses on vapor phase hydration. J. Nucl. Mater. 525, 53-71 (2019).

24. Abrajano, T. A., Bates, J. K. \& Mazer, J. J. Aqueous corrosion of natural and nuclear waste glasses II. Mechanisms of vapor hydration of nuclear waste glasses. J. Non Cryst. Solids 108, 269-288 (1989).

25. Fournier, M., Gin, S. \& Frugier, P. Resumption of nuclear glass alteration: state of the art. J. Nucl. Mater. 448, 348-363 (2014).

26. Neeway, J. J. et al. Vapor hydration of SON68 glass from $90^{\circ} \mathrm{C}$ to $200{ }^{\circ} \mathrm{C}$ : a kinetic study and corrosion products investigation. J. Non Cryst. Solids 358, 2894-2905 (2012).

27. Geisler, T., Dohmen, L., Lenting, C. \& Fritzsche, M. B. K. Real-time in situ observations of reaction and transport phenomena during silicate glass corrosion by fluid-cell Raman spectroscopy. Nat. Mater. 18, 342-348 (2019).

28. Bange, K. et al. Multi-method characterization of soda-lime glass corrosion, part 2. Corrosion in humidity. Glas. Sci. Technol. 75, 20-33 (2002).

29. Collin, M., Fournier, M., Charpentier, T., Moskura, M. \& Gin, S. Impact of alkali on the passivation of silicate glass. npj. Mater. Degrad. 2, 16 (2018)

30. Gin, S. et al. A general mechanism for gel layer formation on borosilicate glass under aqueous corrosion. J. Phys. Chem. C 124, 5132-5144 (2020).

31. Mascaraque, N., Bauchy, M. \& Smedskjaer, M. M. Correlating the network topology of oxide glasses with their chemical durability. J. Phys. Chem. B 121, 1139-1147 (2017).
32. Park, S. Y. \& Lee, S. K. Effects of difference in ionic radii on chemical ordering in mixed-cation silicate glasses: insights from solid-state 170 and $7 \mathrm{Li} \mathrm{NMR} \mathrm{of} \mathrm{Li-Ba}$ silicate glasses. J. Am. Ceram. Soc. 99, 3948-3956 (2016).

33. Collin, M. et al. Structure of international simple glass and properties of passivating layer formed in circumneutral pH conditions. npj. Mater. Degrad. 2, 4 (2018).

34. Greenspan, L. Humidity fixed points of binary saturated aqueous solutions. J. Res. Nbs. A Phy. Ch. 81A, 89 (1977).

35. Riciputi, L. R., Elam, J. M., Anovitz, L. M. \& Cole, D. R. Obsidian diffusion dating by secondary ion mass spectrometry: a test using results from Mound 65, Chalco, Mexico. J. Archaeol. Sci. 29, 1055-1075 (2002).

\section{ACKNOWLEDGEMENTS}

The authors gratefully thank PSL University for the funding of this work, Marie-Hélène Chopinet, Sophie Papin and Kamila Plevacova (Saint-Gobain Recherche, France) for the glass fabrication. Mélanie Moskura (NIMBE, CEA) is acknowledged for her help in conducting the NMR experiments and Nicolas Menguy for having performed the TEM characterizations.

\section{AUTHOR CONTRIBUTIONS}

F.A. carried out the experimental research of this study with the help of I.B., P.L., O.M. and D.C. V.V. performed the experiments, including a rinsing step. O.M. was the main writing author of the paper. T.C. performed the NMR experiments and provided advice to interpret the spectra. A.S. conducted the ToF-SIMS analyses and helped in the interpretation of the profiles.

\section{COMPETING INTERESTS}

The authors declare no competing interests.

\section{ADDITIONAL INFORMATION}

Correspondence and requests for materials should be addressed to O.M.

Reprints and permission information is available at http://www.nature.com/ reprints

Publisher's note Springer Nature remains neutral with regard to jurisdictional claims in published maps and institutional affiliations.

Open Access This article is licensed under a Creative Commons Attribution 4.0 International License, which permits use, sharing, adaptation, distribution and reproduction in any medium or format, as long as you give appropriate credit to the original author(s) and the source, provide a link to the Creative Commons license, and indicate if changes were made. The images or other third party material in this article are included in the article's Creative Commons license, unless indicated otherwise in a credit line to the material. If material is not included in the article's Creative Commons license and your intended use is not permitted by statutory regulation or exceeds the permitted use, you will need to obtain permission directly from the copyright holder. To view a copy of this license, visit http://creativecommons. org/licenses/by/4.0/.

(c) The Author(s) 2020 